\title{
Population Pharmacokinetics and Pharmacodynamics of Vericiguat in Patients with Heart Failure and Reduced Ejection Fraction
}

\author{
Hauke Ruehs ${ }^{1}\left[\right.$ D Dagmar Klein ${ }^{1} \cdot$ Matthias Frei $^{1} \cdot$ Joachim Grevel ${ }^{2} \cdot$ Rupert Austin $^{2} \cdot$ Corina Becker $^{3}$. \\ Lothar Roessig $^{4} \cdot$ Burkert Pieske $^{5,6,7} \cdot$ Dirk Garmann $^{1} \cdot$ Michaela Meyer $^{1}[$
}

Accepted: 8 April 2021 / Published online: 4 June 2021

(c) The Author(s) 2021

\begin{abstract}
Background Vericiguat, a stimulator of soluble guanylate cyclase, has been developed as a first-in-class therapy for worsening chronic heart failure in adults with left ventricular ejection fraction $<45 \%$.

Objective The objective of this article was to characterize the pharmacokinetics and pharmacokinetic variability of vericiguat combined with guideline-directed medical therapy (standard of care), and identify exposure-response relationships for safety (hemodynamics) and pharmacodynamic markers of efficacy ( $N$-terminal pro-B-type natriuretic peptide concentration [NT-proBNP]) in patients with heart failure and left ventricular ejection fraction $<45 \%$ in the SOCRATES-REDUCED study (NCT01951625).

Methods Vericiguat and NT-proBNP plasma concentrations in 454 and 432 patients in SOCRATES-REDUCED, respectively, were analyzed using nonlinear mixed-effects modeling.

Results Vericiguat pharmacokinetics were well described by a one-compartment model with apparent clearance, apparent volume of distribution, and absorption rate constant. Age, bodyweight, plasma bilirubin, and creatinine clearance were identified as significant covariates on apparent clearance; sex and bodyweight on apparent volume of distribution; and bodyweight and plasma albumin level on absorption rate constant. Pharmacokinetic/pharmacodynamic analysis showed initial minor and transient effects of vericiguat on blood pressure with low clinical impact. There were no changes in heart rate following initial or repeated vericiguat administration. An exposure-dependent and time-dependent turnover pharmacokinetic/pharmacodynamic model for NT-proBNP described production and elimination rates and an demonstrated exposure-dependent reduction in [NT-proBNP] by vericiguat plus standard of care compared with placebo plus standard of care. This effect was dependent on baseline [NT-proBNP].

Conclusions Vericiguat has predictable pharmacokinetics, with no long-term effects on blood pressure in patients with heart failure and left ventricular ejection fraction $<45 \%$. A pharmacokinetic/pharmacodynamic model described a vericiguat exposure-dependent reduction of NT-proBNP.
\end{abstract}

Clinical Trial Identifier NCT01951625.

Michaela Meyer

michaela.meyer@bayer.com

1 Pharmacometrics, Bayer AG, Aprather Weg 18a, 42113 Wuppertal, Germany

2 BAST Inc. Limited, Loughborough, UK

3 Clinical Pharmacology, Bayer AG, Wuppertal, Germany

4 Clinical Development, Bayer AG, Wuppertal, Germany

5 Department of Internal Medicine and Cardiology, Charité University Medicine, Campus Virchow-Klinikum, and German Heart Center, Berlin, Germany

6 German Center for Cardiovascular Research (DZHK), Partner Site Berlin, Berlin, Germany

7 Berlin Institute of Health (BIH), Berlin, Germany

\section{Introduction}

Heart failure (HF) with reduced ejection fraction is a major healthcare burden [1-3]. Patients with chronic HF who experience a worsening HF event despite receiving guidelinedirected medical therapy (standard of care $[\mathrm{SoC}]$ ) represent a large proportion of patients who remain at high risk of morbidity and mortality $[4,5] . N$-terminal pro-B-type natriuretic peptide (NT-proBNP) is released in response to ventricular wall stress [6] and is a hallmark biomarker of the presence and severity of HF [7, 8]. Cyclic guanosine monophosphate (cGMP) production via soluble guanylate cyclase (sGC) in the nitric oxide-sGC-cGMP pathway is essential for normal cardiac and vascular function [9-12]. However, the nitric 


\section{Key Points}

Vericiguat pharmacokinetics as well as exposureresponse relationships for pharmacodynamic markers of safety (hemodynamics) and efficacy ( $N$-terminal pro-Btype natriuretic peptide plasma concentration [NT-proBNP]) were investigated in patients with heart failure and left ventricular ejection fraction $<45 \%$

Vericiguat combined with guideline-directed medical therapy (standard of care) had no long-term effects on blood pressure in patients with heart failure and left ventricular ejection fraction $<45 \%$

Reductions in [NT-proBNP] with vericiguat treatment combined with standard of care were dependent on vericiguat exposure as well as baseline [NT-proBNP] and led to a stronger NT-proBNP decrease with vericiguat than with standard of care alone

oxide-sGC-cGMP pathway is impaired in HF, which leads to a deficiency in cGMP [13]. Stimulating sGC to produce cGMP represents a pathway not currently addressed by SoC.

Vericiguat is a first-in-class direct sGC stimulator for the treatment of adult patients with chronic HF (and left ventricular ejection fraction $[\mathrm{LVEF}]<45 \%$ ) that reduces the risk for the composite endpoint of death from cardiovascular causes or hospitalization [14-16]. Vericiguat (oral tablet formulation, $<15 \mathrm{mg}$ ) is rapidly absorbed and demonstrates linear pharmacokinetics in healthy volunteers [17]. The main metabolic pathway of vericiguat is glucuronidation via uridine diphosphate-glucuronosyltransferase (UGT) isoforms UGT1A1 and UGT1A9 [18], expressed in the liver and both liver and kidneys, respectively $[19,20]$. The pharmacodynamic (PD) effects on the safety and efficacy of vericiguat treatment were evaluated in the phase II study SOluble guanylate Cyclase stimulatoR in heArT failurE patientS (SOCRATES)-REDUCED (NCT01951625 [21]) and in the phase III VICTORIA study [15] in patients with HF and a reduced LVEF $(<45 \%)$.

Evaluation of SOCRATES-REDUCED data showed vericiguat $\leq 10 \mathrm{mg}$ was well tolerated, with no significant effect on change in NT-proBNP at 12 weeks (pooled vericiguat 2.5, 5 , and $10 \mathrm{mg}$ on top of SoC compared with placebo on top of SoC) [21]. However, exploratory secondary analyses of change in log-transformed NT-proBNP level from baseline to 12 weeks, using linear regression modeling, suggested a dose-response relationship $(p<0.02)$.

In this article, SOCRATES-REDUCED data are used to describe the population pharmacokinetics of vericiguat and pharmacokinetic (PK) variability and to investigate the exposure-response relationships for PD markers of safety (hemodynamics) and efficacy (NT-proBNP). A semi-mechanistic PK/PD model was also developed to characterize the exposure-NT-proBNP relationship corresponding to the previously suggested dose-response relationship.

\section{Methods}

\subsection{Study Design}

The design of SOCRATES-REDUCED, a multicenter, randomized, double-blind, placebo-controlled, dose-finding, phase II study, has been described previously [21, 22]. In brief, 456 patients with HF and LVEF $<45 \%$ were randomized to five equally sized treatment groups (one placebo group and four vericiguat treatment groups). Active treatment groups had a target maximal daily dose of 1.25, 2.5, 5, and $10 \mathrm{mg}$ of vericiguat. All active treatment groups, except the $1.25 \mathrm{mg}$ group, started at vericiguat $2.5 \mathrm{mg}$ once daily (visit 1). Up-titration to target dose was based on blood pressure (BP) values and tolerability at week 2 (visit 2) and week 4 (visit 3) [21]. Treatment duration was 12 weeks.

\subsection{PK Data Sampling}

Blood samples were taken at baseline/trough at visits 2-4 (prior to study drug) and at Visit 5; at Visits 1 and 3, 1-3 and 4-6 h post-study drug dosing; and at Visits 2 and 4, 1-3 h post-study drug dosing. This sparse PK sampling was demonstrated to be suitable for developing robust population PK models prior to implementing into the SOCRATESREDUCED phase II study. Following a simulation re-estimation approach, structural population PK models were developed on virtual sparse PK samples derived from physiologically based PK predictions for virtual patients with HF. The individual post-hoc estimates for area under the plasma concentration-time curve (AUC) and maximum plasma drug concentration $\left(C_{\max }\right)$ from the patient population PK model were compared with those derived from the patient physiologically based PK model. As all model parameters were estimated with acceptable uncertainty, we concluded that the population PK model for vericiguat would be sufficiently informed with this sparse sampling design (data not shown). A summary of the PK sampling is provided in Table 1 of the Electronic Supplementary Material (ESM). The methodologies regarding the PK assessments of vericiguat have been previously described $[23,24]$. Method validation and analysis of the study samples were performed in accordance with the bioanalytical method validation guidance for industry of the US Food and Drug Administration [25]. 


\subsection{PD Data Sampling}

Pharmacodynamic data were obtained after patients had rested for at least 10 minutes in a sitting position. Vital signs (i.e., systolic BP [SBP] and heart rate [HR]) were measured at 2-minute intervals prior to and at $2 \mathrm{~h} \pm 15$ minutes poststudy drug dosing at screening and visits $1-5$. Plasma concentrations of NT-proBNP ([NT-proBNP]) were measured at screening and at visits $1-5$ and were analyzed with the Elecsys proBNP II Kit (Roche Diagnostics, Indianapolis, IN, USA).

\subsection{Population PK Modeling}

Data were analyzed via nonlinear mixed-effects modeling using NONMEM (Icon Development Solutions, Ellicott City, Maryland, USA, Version 7.2) with the Navigator workbench (Mango Solutions, Chippenham, UK, Version 9.1.5146) in a Red Hat Enterprise Linux 6.3 environment. Models were evaluated with R scripts (The R Foundation for Statistical Computing, Vienna, Austria, Version 3.2.5 [26]) and PsN (Version 3.4.1 with Perl, Version 5.10.1).

First, a PK base model was developed that provided the compartmental structure of the model and defined the parameters in which inter-individual variability (IIV) was quantified. A PK covariate model was then developed in which covariates, such as demographics and measurable physiological information, were tested for between-subject variability. As the metabolic pathway of vericiguat involves glucuronidation via UGTs in the liver and kidneys, bilirubin, serum creatinine, creatinine clearance $\left(\mathrm{CL}_{\mathrm{CR}}\right)$ [27], and $\mathrm{CL}_{\mathrm{CR}}$ standardized to a body weight of $70 \mathrm{~kg}$ (standardized $\mathrm{CL}_{\mathrm{CR}}$ ) [28] were investigated as covariates. Following graphical analysis, an exponential function was used to implement continuous covariates (i.e., division of the individual value by the population median and the result being raised to an estimated power). Covariates were manually included stepwise into the model if $\chi^{2}$ testing showed significance $(p<0.01)$ [29]. Subsequently, covariates were stepwise removed if they did not show a significant worsening $(p<0.001)$, yielding the final covariate model.

Deterministic simulations were carried out to assess the quantitative translation of the 5th and 95th percentiles of a covariate from the final model into relative change in PK exposure parameters (AUC and $C_{\max }$ at steady state) compared with a typical patient. To illustrate the robustness and the predictive performance of the final covariate model, prediction-corrected visual predictive checks (VPCs) were conducted for vericiguat treatment arms [30,31]. Visual predictive checks (on visits 1-5) showed individual vericiguat concentration-time data, $90 \%$ prediction intervals, and the median with the corresponding $95 \%$ confidence intervals (CIs) of 1000 stochastic simulations based on the original dataset using the final vericiguat population PK model.

Individual estimates of PK parameters were used in the simulation of the AUC variable for each patient. The variable for vericiguat exposure used in the PK/PD modeling was the 24-h AUC updated at 24-h intervals from the first vericiguat dose. The PK base model was used to generate PK/PD simulations.

\subsection{PK/PD Correlation Analysis}

Individual parameter estimates were used to calculate individual exposures on day 1 and at steady state; patient dropouts were not included. On day $1, C_{\max }$ and area under the plasma concentration-time curve from time 0 to $24 \mathrm{~h}\left(\mathrm{AUC}_{24}\right)$ were determined from the first intake of the study drug to the subsequent intake of the study drug or at maximum $24 \mathrm{~h}$. On the last treatment day, the maximum observed plasma drug concentration and area under the plasma concentration-time curve from the last intake of study drug until $24 \mathrm{~h}$ after $\left(C_{\text {max }, \mathrm{ss}}\right.$ and $\mathrm{AUC}_{\tau, \mathrm{ss}}$, respectively) were determined. Linear regression was performed with the "Im" function in R, Version 3.2.5 [26]. Regression lines and corresponding 95\% CIs were plotted. Significance was determined if $p$ values were $<0.05$.

To investigate hemodynamic effects of vericiguat at the start and end of treatment, $C_{\max }$ was correlated with the change in SBP and HR from pre-dose to post-dose (both visit 1), and the $C_{\max , \mathrm{ss}}$ was correlated with the change of SBP and of HR from pre- to post-dose at week 8 (visit 4), assuming steady state of vericiguat was reached. Week 12 (visit 5) values were excluded from correlation analyses because the last drug intake occurred 1 day before visit 5 and, therefore, vericiguat plasma concentrations would be expected to be below steady-state trough concentrations.

\subsection{PK/PD Modeling of NT-proBNP}

A PK/PD turnover model was developed to describe the relationship between vericiguat exposure and the time course of NT-proBNP. The aim was to use simulations from the model to visualize the NT-proBNP time profile from when vericiguat was administered on top of $\mathrm{SoC}$ during the first 12 weeks and over the 8 weeks following cessation of study drug, and to compare this with the net simulated effect of SoC. Overall, 20 weeks were simulated.

To illustrate the robustness and the predictive performance of the PK/NT-proBNP model, VPCs were conducted for absolute [NT-proBNP] over time for all patients and for NT-proBNP baseline $_{\text {quartiles of the population: }}$ 
- Lowest quartile: [NT-proBNP] $]_{\text {baseline }} \leq 1559 \mathrm{pg} / \mathrm{mL}$ (lowest $[\mathrm{NT} \text {-proBNP }]_{\text {baseline }}$ value was $94.1 \mathrm{pg} / \mathrm{mL}$ ).

- Second quartile: $1559 \mathrm{pg} / \mathrm{mL}<[\mathrm{NT}-\mathrm{proBNP}]_{\text {baseline }}$ $\leq 3000 \mathrm{pg} / \mathrm{mL}$.

- Third quartile: $3000 \mathrm{pg} / \mathrm{mL}<[\mathrm{NT} \text {-proBNP }]_{\text {baseline }}$ $\leq 6246 \mathrm{pg} / \mathrm{mL}$.

- Fourth quartile: [NT-proBNP] $]_{\text {baseline }}>6246 \mathrm{pg} / \mathrm{mL}$ (highest [NT-proBNP] $]_{\text {baseline }}$ value was $69,720 \mathrm{pg} / \mathrm{mL}$ ).

[NT-proBNP] $]_{\text {baseline }}$ ranged from $94.1 \mathrm{pg} / \mathrm{mL}$ to 69,720 $\mathrm{pg} / \mathrm{mL}$. To illustrate the behavior of the model, time profiles for typical individuals with six [NT-proBNP $]_{\text {baseline }}$ values were simulated $(250,500,1000,3000,5000$, and 10,000 $\mathrm{pg} / \mathrm{mL}$ ). In addition, the absolute change in [NT-proBNP] from baseline corrected by placebo (SoC arm) over time was visualized.

Finally, simulations were carried out according to the design of the study for scenarios of the five cohorts (one placebo and four treatment arms), each with 500 patients, and were used to visualize the placebo-corrected, dose-dependent effect of vericiguat on changes in [NT-proBNP] from baseline. Simulation results were summarized by boxplots of the ratio below (Eq. 1), calculated from each simulation repeat relative to SoC. Box-Cox transformation was applied, followed by retransformation back to the original scale.

$$
\frac{\operatorname{Median}\left(\frac{[\mathrm{NT}-\text { proBNP }]_{\text {day84 }}}{[\mathrm{NT}-\mathrm{proBNP}]_{\text {baseline }}}\right)}{\operatorname{Median}\left(\frac{[\mathrm{NT}-\text { proBNP }]_{\text {day84 }}}{[\mathrm{NT}-\text { proBNP}]_{\text {baseline }}}\right)}
$$

\section{Results}

\subsection{Data}

For the PK analysis, data from 454 patients with PK samples from 456 randomized patients [21] were available. A total of 363 patients received vericiguat treatment during the study, from which 3376 plasma samples were eligible for exposure analysis. Twenty-two plasma concentrations were excluded, as the dosing records of the respective patients were not explicit for the last dosing event; 17 plasma concentrations of patients within the placebo arm were excluded because of levels above the lower limit of quantification. For the PK/PD correlation analysis of SBP and HR, paired $C_{\max }$ and PD values available from visits 1 and 2 were used. For the PK/PD analysis of NT-proBNP, 2347 eligible samples were collected from 432 patients (Fig. 1). At baseline, the measured [NT-proBNP] ranged from $94.1 \mathrm{pg} / \mathrm{mL}$ to $69,724 \mathrm{pg} / \mathrm{mL}$. Although the inclusion criterion of the study was $\geq 1000 \mathrm{pg} / \mathrm{mL}$ for screening at local laboratories, the cut-off for central laboratory NT-proBNP measurement may have been lower during randomization.

\subsection{Base Model}

The patients' PK data were sufficiently described by a onecompartment model parameterized by apparent clearance $(\mathrm{CL} / F)$ and apparent volume of distribution $(V / F)$, as only PK data after oral absorption were available. The absorption process was described by an absorption rate constant $\left(k_{\mathrm{a}}\right)$. Including a lag time did not improve the fit of the model. The parameters $\mathrm{CL} / F$ and $V / F$ showed a high degree of correlation that was eventually included in the model. Population mean estimates (inter-individual variability [\%]) for $\mathrm{CL} / F$,

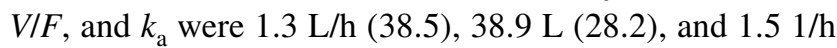
(103.0), respectively. Relative standard error and shrinkage were acceptable for all parameters, IIV was in an acceptable range, although rather high for $k_{\mathrm{a}}$. The high IIV for $k_{\mathrm{a}}$ was not unexpected in this population with such severe disease and within which food intake is less standardized than in a phase I trial (especially with respect to composition and timing relative to drug administration), thus reflecting a more "real-world" setting. Model parameters of the PK base model are given in Table 1. An overview of the model development is shown in Table 2 of the ESM.

\subsection{Covariate Model}

Prior to the covariate analysis, the parameter describing the correlation between $\mathrm{CL} / F$ and $V / F$ was removed from the PK base model, as it seemed likely that the correlation arose from a common covariate. By visual inspection, the correlation between covariates ranged from low (e.g., standardized $\mathrm{CL}_{\mathrm{CR}}$ vs age) to strongly correlated (e.g., lean body mass vs body mass; data not shown).

Visual inspection of the parameter vs covariate plots from the PK base model indicated that body size affected systemic clearance and $\mathrm{V} / F$. Thus, the model parameters $\mathrm{CL} / F$ and $V / F$ were allometrically scaled by bodyweight [32] (Eqs. 2 and 3), which resulted in a significant decrease of the objective function value.

$\mathrm{CL} / F_{i}=\mathrm{CL} / F \times\left(\frac{\text { body weight }_{i}}{\text { median body weight }}\right)^{3 / 4}$

$V / F_{i}=V / F \times\left(\frac{\text { body weight }_{i}}{\text { median body weight }^{1}}\right.$

Other relationships examined were age, bilirubin level, and standardized $\mathrm{CL}_{\mathrm{CR}}$ on $\mathrm{CL} / F$, sex on $V / F$, and albumin, bodyweight, and race on $k_{\mathrm{a}}(p<0.01)$, with 


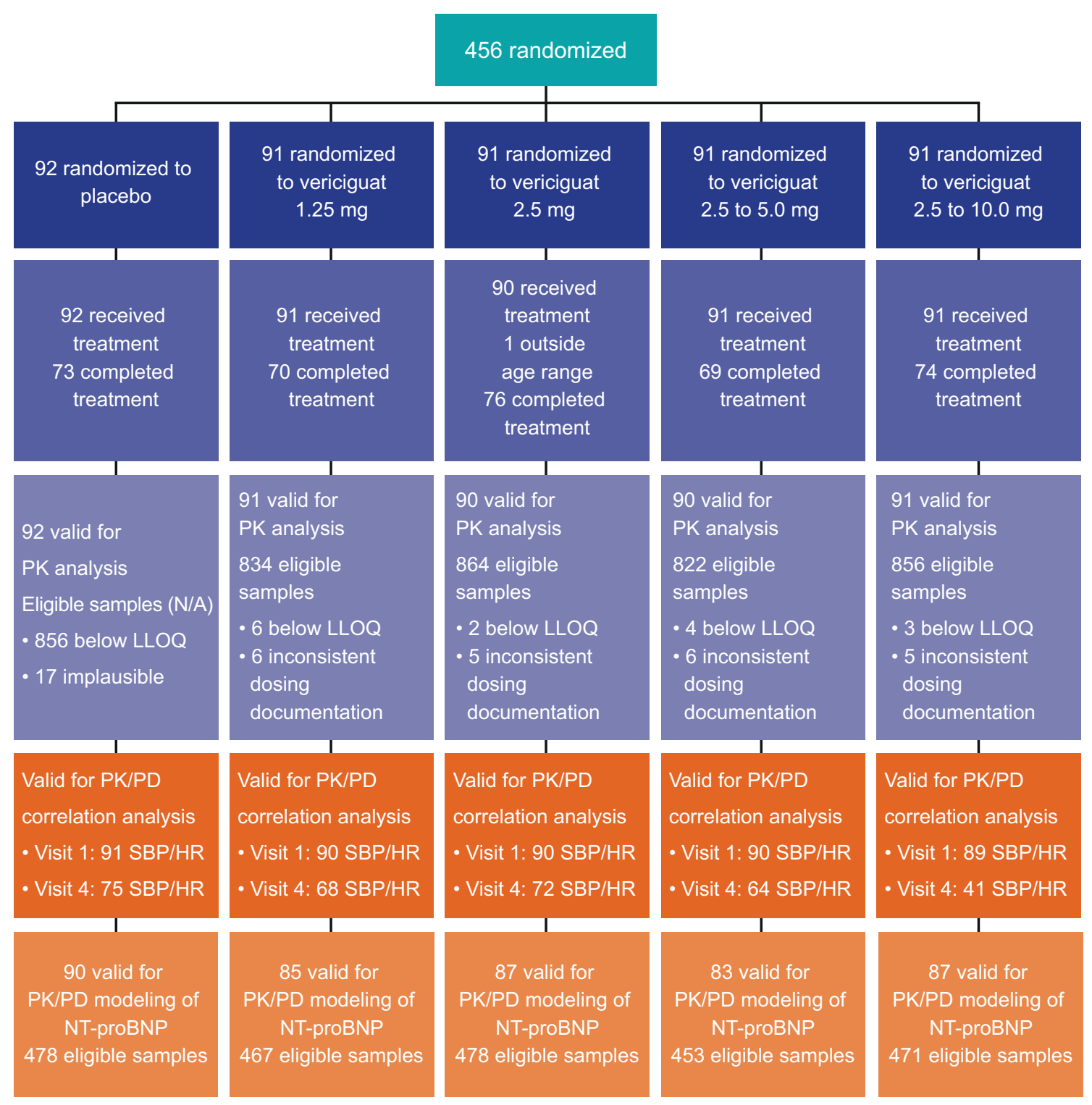

Fig. 1 Flow of patients through the SOCRATES-REDUCED study and eligible samples for vericiguat pharmacokinetic (PK) and PK/pharmacodynamic (PD) analyses. $H R$ heart rate, $L L O Q$ lower limit of quantification, N/A not applicable, SBP systolic blood pressure

bodyweight, $\mathrm{CL}_{\mathrm{CR}}$, albumin, and bilirubin being time-varying covariates. Race on $k_{\mathrm{a}}$ was subsequently eliminated $(p<0.001)$. Allometric scaling of $\mathrm{CL} / F$ and $V / F$ resulted in a reduction exceeding $30 \%$ of the corresponding IIV and a large decrease of the objective function value. Inclusion of age as a covariate on CL/F reduced IIV by $14.7 \%$, whereas the other covariate relationships ( $\mathrm{sex}, \mathrm{CL}_{\mathrm{CR}}$, bilirubin, and albumin) had effects of $<10 \%$ (Table 3 of the ESM). Correlation between age, bodyweight, and standardized $\mathrm{CL}_{\mathrm{CR}}$ was low to moderate, enabling the differentiation between their effect on $\mathrm{CL} / F$.

None of the additional covariates, including baseline NT-proBNP, atrial fibrillation, New York Heart Association class, or time-varying covariates examined, such as concomitant medication (i.e., cytochrome P450 3A4, P-glycoprotein, UGT1A9, breast cancer resistant protein, and UGT1A1 inhibitors), were significant. A subsequent test of the impact of dose on the bioavailability parameter $\mathrm{F}$ revealed that $\mathrm{F}$ decreased with increasing dose $(100 \%$ at $1.25 \mathrm{mg}$ to $89 \%$ at $2.5 \mathrm{mg}, 79 \%$ at $5 \mathrm{mg}$, and $71 \%$ at $10 \mathrm{mg}$ ). This corresponds to a decreased dose-normalized geometric mean of the apparent $\mathrm{AUC}_{\tau, \mathrm{ss}}$ from $100 \%$ at $1.25 \mathrm{mg}$ to $82 \%$ at $10 \mathrm{mg}$. The fixed-effects and random-effects parameters and the associated precisions (relative standard error expressed as percent; $\%$ relative standard error) for the final vericiguat model are shown in Table 2. Descriptive statistics of PK estimates of the final covariate PK model with dose are summarized in Table 4 of the ESM. 
Table 1 Model parameters of the pharmacokinetic base model

\begin{tabular}{llllll}
\hline Parameter & Value & RSE $(\%)$ & $\begin{array}{l}\text { Inter-individual } \\
\text { variability CV }(\%)^{\mathrm{a}}\end{array}$ & RSE (\%) & Shrinkage (\%) \\
\hline $\mathrm{CL} / F(\mathrm{~L} / \mathrm{h})$ & 1.3 & 2.09 & 38.47 & 8.33 & $6.18^{\mathrm{d}}$ \\
Correlation $(\mathrm{CL} / F \sim V / F)$ & 0.70 & 11.9 & & & \\
$V / F(\mathrm{~L})$ & 38.9 & 2.18 & 28.23 & 12.5 & $19.5^{\mathrm{d}}$ \\
$k_{\mathrm{a}}(1 / \mathrm{h})$ & 1.5 & 9.53 & 102.99 & 18.5 & $37.2^{\mathrm{d}}$ \\
Proportional error $(\%)$ & $26.02^{\mathrm{b}}$ & 4.37 & & & $8.91^{\mathrm{e}}$ \\
Additive error $(\mu \mathrm{g} / \mathrm{L})$ & $7.81^{\mathrm{c}}$ & 14.6 & & $8.91^{\mathrm{e}}$ \\
\hline
\end{tabular}

$C L / F$ apparent clearance, $C V$ coefficient of variation, $k_{a}$ absorption rate constant, $P K$ pharmacokinetic, $R S E$ relative standard error, $V / F$ apparent volume of distribution

${ }^{a}$ The $\mathrm{CV} \%$ is calculated by SQRT[EXP $\left.\left(\mathrm{OMEGA}^{2}\right)-1\right] \times 100[40]$

${ }^{\mathrm{b}}$ The $\mathrm{CV}$ is calculated by SQRT(SIGMA $\left.{ }^{2}\right) \times 100$

${ }^{\mathrm{c}}$ The standard deviation is calculated by SQRT(SIGMA ${ }^{2}$ )

${ }^{\mathrm{d}}$ The shrinkage is calculated by $100 \% \times\left[1-\mathrm{SD}(\mathrm{ETA}) / \mathrm{SQRT}\left(\mathrm{OMEGA}^{2}\right)\right]$

${ }^{\mathrm{e}}$ The Epsilon shrinkage is calculated by $100 \% \times[1-\mathrm{SD}(\mathrm{IWRES})]$
Prediction-corrected VPCs confirmed the qualification of the final covariate model for vericiguat (Fig. 2). The VPCs revealed that PK model simulations concur with the data and support the robustness of the population model. Goodnessof-fit plots for the final population PK model are depicted in Fig. 1 of the ESM. The influence of significant covariates on relative PK exposure change is visualized as forest plots in Fig. 2 of the ESM.

\subsection{PK/PD Correlation Analysis}

Linear regression analysis showed a short-term hemodynamic response of an exposure-dependent decrease of SBP on day 1 after vericiguat intake (Fig. 3). Linear regression of SBP change vs $C_{\max }$ differed from $0(p=0.047)$. However, at visit 4 , there was no longer a significant dependency of SBP on vericiguat exposure ( $p=0.528$; Fig. 4 ; Table 5 of the ESM). For HR, no changes from pre-dose to post-dose were observed for visit 1 or visit 4 (data not shown).

\subsection{Turnover PK/PD Model for NT-proBNP}

The established semi-mechanistic exposure-response model for NT-proBNP was a turnover model describing the dynamics of plasma NT-proBNP concentrations (Fig. 5 and Eq. 4), where [NT-proBNP] is the plasma concentration of NT-proBNP, $k_{i n}$ is a zero-order rate constant describing the production of NT-proBNP, $k_{\text {out }}$ is a first-order rate constant describing the elimination of NT-proBNP, and $[\mathrm{NT} \text {-proBNP }]_{\text {baseline }}$ is the plasma NT-proBNP concentration at baseline. $k_{\text {in }}$ and $k_{\text {out }}$ were not influenced by covariates, and IIV was included in $k_{\text {in }}$ and [NT-proBNP] $]_{\text {baseline. }}$. Based on previously reported data [33], a dependence of $k_{\text {out }}$ on the model-predicted [NT-proBNP] was considered, which improved the model.

In the resultant model, $k_{\text {out_max }}$ denotes the maximum value of $k_{\text {out }}$, which could be reduced by increasing [NT-proBNP] by a proportion given by the maximal effect $\left(E_{\max }\right)$. The concentration of a drug that gives half-maximal response $\left(\mathrm{EC}_{50}\right)$ reflects [NT-proBNP], whereby the inhibition of $k_{\text {out_max }}$ is half its maximum extent (Eq. 5).

The time-varying 24-h AUC of vericiguat inhibits $k_{i n}$ through a linear drug effect model with parameter active treatment effect (ATRT; Eq. 6). The resulting $\Delta$ objective function value of -5.00 was significant at $p=0.05$ but not at $p=0.01$ according to the $\chi^{2}$ distribution. The $95 \%$ CIs around all parameter estimates from the NT-proBNP model, derived from a bootstrap run that utilized 500 resamplings of the original dataset, exclude the null value of zero (Table 3). Of the 500 bootstrap runs, 488 completed with successful minimization and only six were $<0$, indicating that the observation of a statistically significant positive estimate of ATRT was unlikely to have been influenced by a small number of patients who responded particularly strongly to vericiguat treatment.

$$
\begin{aligned}
& \frac{\mathrm{d}[\mathrm{NT}-\text { proBNP }]}{\mathrm{d} t}=k_{\text {in }}-k_{\text {out }} \times[\mathrm{NT}-\text { proBNP }] \\
& k_{\text {out }}=k_{\text {out } \_ \text {max }} \times\left(1-\frac{E_{\max } \times[\mathrm{NT}-\text { proBNP }]}{E C_{50}+[\mathrm{NT}-\text { proBNP }]}\right) \\
& k_{\text {in }}= \\
& \quad T V k_{\text {in }} \times\left(1+\theta_{k_{\mathrm{in}}, \mathrm{NT}-\text { proBNP }} \times\left(\ln \left([\mathrm{NT} \text {-proBNP }]_{\text {baseline }}\right)-8.03\right)\right) \\
& \times(1-\mathrm{ATRT} \times \mathrm{AUC})
\end{aligned}
$$


Table 2 Model parameters of the final pharmacokinetic covariate model with dose

\begin{tabular}{|c|c|c|c|c|c|}
\hline Parameter & Value & $\operatorname{RSE}(\%)$ & $\begin{array}{l}\text { Inter-individual } \\
\text { variability } \\
\text { CV }(\%)^{\mathrm{a}}\end{array}$ & $\operatorname{RSE}(\%)$ & Shrinkage $(\%)$ \\
\hline $\mathrm{CL} / F(\mathrm{~L} / \mathrm{h})$ & 1.24 & 3.19 & 25.1 & 9.23 & $10.2^{\mathrm{e}}$ \\
\hline$V / F(\mathrm{~L})$ & 34.3 & 2.12 & 21.0 & 16.5 & $34.7^{\mathrm{e}}$ \\
\hline$k_{\mathrm{a}}(1 / \mathrm{h})$ & 1.29 & 9.54 & 117 & 16.7 & $35.2^{\mathrm{e}}$ \\
\hline$\theta_{\mathrm{CL}, \text { age }}$ & -0.418 & 20.5 & & & \\
\hline$\theta_{\mathrm{CL}, \text { bodyweight }}$ & $0.75^{\mathrm{b}}$ & n.a. & & & \\
\hline$\theta_{\mathrm{CL} \text {,standardized creatinine clearance }}$ & 0.164 & 26.1 & & & \\
\hline$\theta_{\mathrm{CL}, \text { bilirubin }}$ & -0.072 & 26.1 & & & \\
\hline$\theta_{\mathrm{V}, \text { bodyweight }}$ & $1.00^{\mathrm{b}}$ & n.a. & & & \\
\hline$\theta_{\mathrm{V}, \text { sex }}$ & 0.850 & 4.09 & & & \\
\hline$\theta_{\text {ka,bodyweight }}$ & 1.28 & 25.2 & & & \\
\hline$\theta_{\text {ka,albumin }}$ & 2.37 & 26.1 & & & \\
\hline$\theta_{\mathrm{F}, \mathrm{dose}} \leq 1.25 \mathrm{mg}$ & 1.08 & 2.62 & & & \\
\hline$\theta_{\mathrm{F}, \text { dose }}=5 \mathrm{mg}$ & 0.867 & 1.94 & & & \\
\hline$\theta_{\mathrm{F}, \mathrm{dose}=10 \mathrm{mg}}$ & 0.793 & 2.60 & & & \\
\hline Proportional error (\%) & $25.7^{\mathrm{c}}$ & 4.21 & & & $8.4^{\mathrm{f}}$ \\
\hline Additive error $(\mu \mathrm{g} / \mathrm{L})$ & $7.27^{\mathrm{d}}$ & 14.9 & & & $8.4^{\mathrm{f}}$ \\
\hline
\end{tabular}

$C L / F$ apparent clearance, $C V$ coefficient of variation, $F$ estimate of absolute bioavailability dependent on dose size, $k_{a}$ absorption rate constant, $R S E$ relative standard error, $V / F$ apparent volume of distribution

${ }^{a}$ The $\mathrm{CV} \%$ is calculated by SQRT[EXP(OMEGA $\left.\left.{ }^{2}\right)-1\right] \times 100$

${ }^{\mathrm{b}}$ Fixed value

${ }^{\mathrm{c}}$ The $\mathrm{CV}$ is calculated by SQRT $\left(\mathrm{SIGMA}^{2}\right) \times 100$

${ }^{\mathrm{d}}$ The standard deviation is calculated by SQRT(SIGMA ${ }^{2}$ )

${ }^{e}$ ETA shrinkage is calculated by $100 \% \times\left[1-\mathrm{SD}(\mathrm{ETA}) / \mathrm{SQRT}\left(\mathrm{OMEGA}^{2}\right)\right]$

${ }^{\mathrm{f}}$ Epsilon shrinkage is calculated by $100 \% \times[1-\mathrm{SD}(\mathrm{IWRES})]$

Parameter covariate relations were described as:

$$
\begin{aligned}
& F=\left\{\begin{array}{l}
1.08, \text { Dose } \leq 1.25 \mathrm{mg} \\
1, \text { Dose }=2.5 \mathrm{mg} \\
0.867, \text { Dose } \leq 5 \mathrm{mg} \\
0.793, \text { Dose } \leq 10 \mathrm{mg}
\end{array}\right. \\
& \frac{\mathrm{CL}}{F}=1.24 \times\left(\frac{\text { Age }}{68}\right)^{-0.418} \times\left(\frac{\text { Bilirubin }}{0.6}\right)^{-0.075} \times\left(\frac{\mathrm{CL}_{\mathrm{Cr}, \mathrm{st}}}{100}\right)^{0.164} \times\left(\frac{\text { Weight }}{70}\right)^{3 / 4} \\
& \frac{V}{F}=3.43 \times \mathrm{SEX} \times\left(\frac{\text { Weight }}{70}\right), \text { with SEX }=\left\{\begin{array}{l}
1, \text { male } \\
0.850, \text { female }
\end{array}\right. \\
& k_{\mathrm{a}}=1.29 \times\left(\frac{\text { Albumin }}{4.0}\right)^{2.37} \times\left(\frac{\text { Weight }}{70}\right)^{1.28}
\end{aligned}
$$

\subsubsection{Qualification of the NT-proBNP Model}

The NT-proBNP model was qualified by a VPC using 2000 repeat simulations of the data set. The respective VPC, stratified by quartiles of [NT-proBNP $]_{\text {baseline }}$, is given in Fig. 6 . For each quartile, the model adequately described the central tendency and the data variability.

\subsubsection{Application of the NT-proBNP Model}

The PK/PD model for NT-proBNP was used to simulate time profiles for 20 weeks with vericiguat $10 \mathrm{mg}$ on top of SoC vs SoC alone (placebo group) for [NT-proBNP $]_{\text {baseline }}$ values from 250 to $10,000 \mathrm{pg} / \mathrm{mL}$ (Fig. 7). Overall, vericiguat, on top of SoC, led to a stronger NT-proBNP decrease than SoC alone for all simulated [NT-proBNP] $]_{\text {baseline }}$ categories. Furthermore, simulations using patient data assigned to quartiles of [NT-proBNP $]_{\text {baseline }}$ and box plots of NT-proBNP 


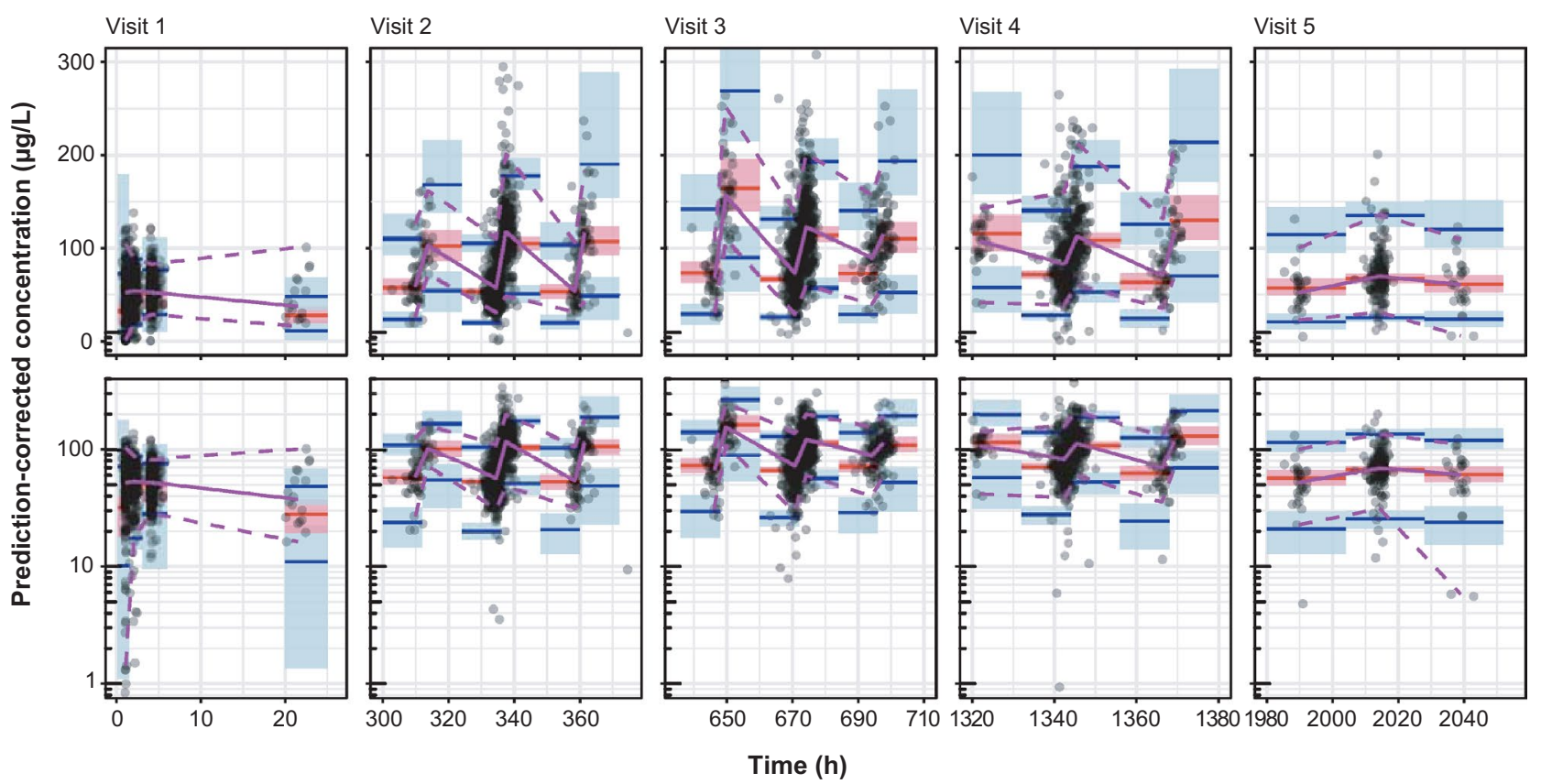

Fig. 2 Prediction-corrected visual predictive checks of the final covariate model at visits $1-5$. The upper row shows the normal scale and the lower row shows the log scale of the prediction-corrected concentrations. In Visits $2-5$, time is shown $\pm 24 \mathrm{~h}$ around the planned time. Solid purple line: median prediction-corrected data.
Dashed purple lines: $90 \%$ prediction interval of prediction-corrected data. Solid red line: median model predictions. Solid blue lines: $90 \%$ interval. Boxes indicate the $95 \%$ confidence intervals around the corresponding model predictions. Circles: prediction-corrected observed vericiguat plasma concentration-time data
Fig. 3 Systolic blood pressure (SBP) change vs vericiguat maximum observed concentration $\left(C_{\max }\right)$. Correlation of $C_{\max }$ with change in SBP from pre-dose to post-dose (first dose of study medication) at visit 1 . Open symbols represent data from individual patients belonging to different treatment arms (black: placebo, dark blue: 1.25 mg, teal: $2.5 \mathrm{mg}$ ). The red solid line depicts the linear regression model. The $95 \%$ confidence interval $(\mathrm{CI})$ of the regression model is represented by red dashed lines

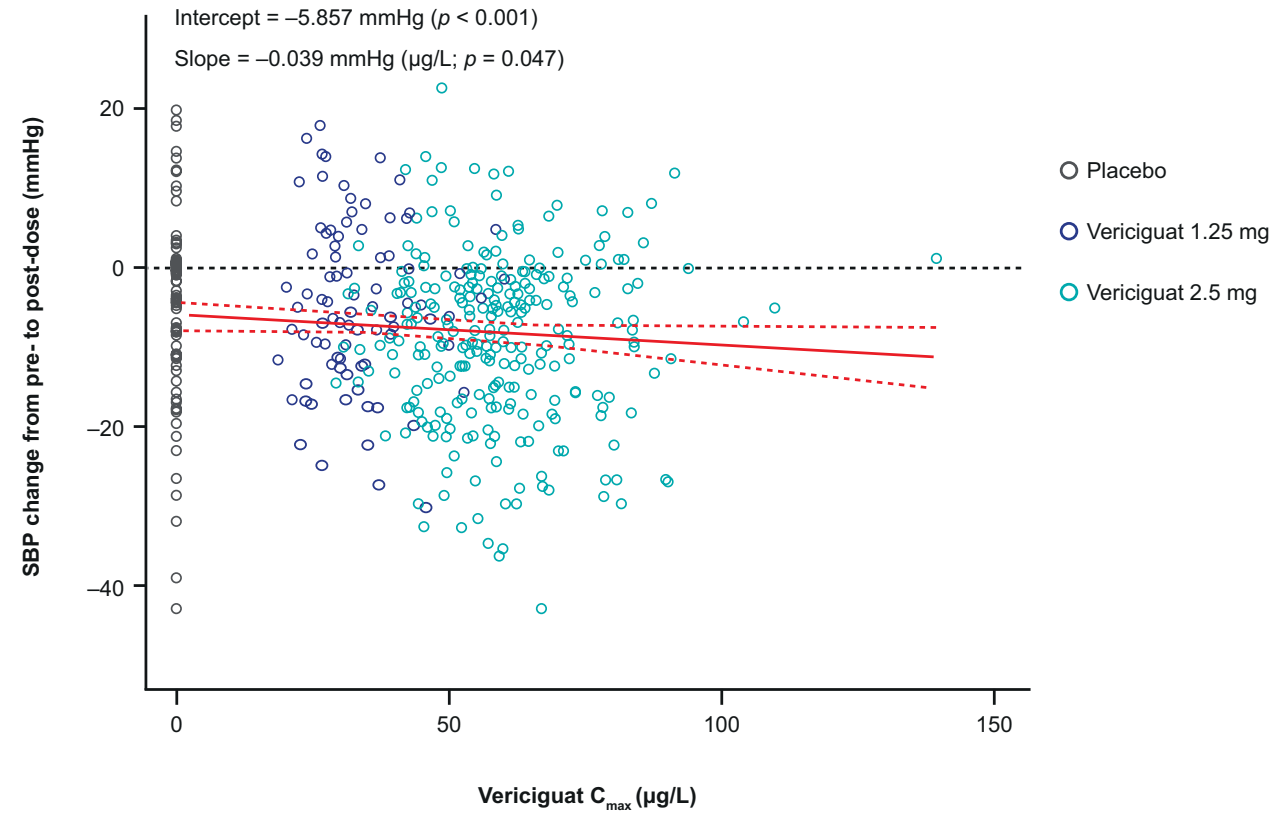

PK/PD showing a simulation of vericiguat on top of SoC, expressed as a ratio of SoC alone, were generated (Fig. 8). Simulation results from each actively treated cohort are shown relative to SoC. The relative effectiveness of vericiguat treatment in lowering [NT-proBNP] decreases with increasing quartile of $[\mathrm{NT} \text {-proBNP }]_{\text {baseline. Each category }}$ within each of the five boxplot panels in Fig. 8 contains the results from 500 repeated simulations, each involving approximately 125 patients. 
Fig. 4 Systolic blood pressure (SBP) change vs vericiguat maximum observed concentration at steady state $\left(C_{\max , \mathrm{ss}}\right)$. Correlation of $C_{\mathrm{max}, \mathrm{ss}}$ with pre-dose to post-dose change of SBP at week 8 (visit 4). Open symbols represent data from individual patients belonging to different treatment arms (black: placebo, dark blue: 1.25 $\mathrm{mg}$, teal: $2.5 \mathrm{mg}$, green: $5 \mathrm{mg}$, orange: $10 \mathrm{mg}$ ). The red solid line depicts the linear regression model. The $95 \%$ confidence interval (CI) of the regression model is represented by dashed lines

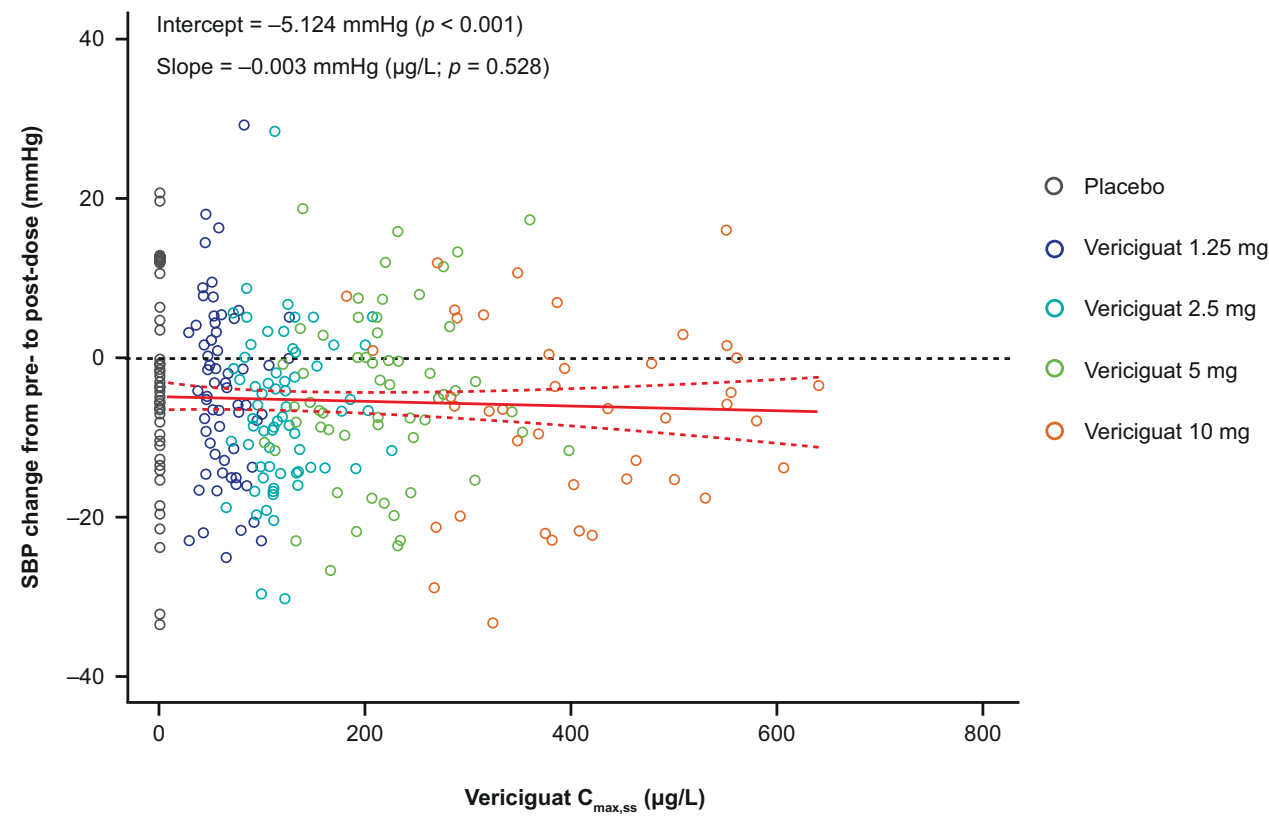

(vericiguat $\leq 15 \mathrm{mg}$ ) [17], likely due to variability covering the effect at small sample sizes. Single-dose studies demonstrated close to linear pharmacokinetics of vericiguat for AUC and a slight trend in decreasing $C_{\max }$ with increasing doses.

The covariate analysis showed age had the most pronounced effect on the pharmacokinetics of all tested parameters, with increased age correlating with reduced CL/F. In this patient population, higher age was associated with more severe disease phenotypes, indicated by baseline NTproBNP and reduced renal function. As bodyweight also correlated with CL/F and $V / F$, the model parameters CL/F and $V / F$ were allometrically scaled by bodyweight, improving the model fit. Creatinine clearance was also a significant covariate, with $<10 \%$ effect on clearance. In line with this, urinary excretion of vericiguat in healthy volunteers was $<10 \%$ [17].

Bilirubin level was negatively correlated with $\mathrm{CL} / F$, which may be due to the glucuronidation and excretion of bilirubin via bile, similar to vericiguat [34]. Reduced biliary secretion (and thus vericiguat clearance) will likely be associated with higher levels of bilirubin (and vericiguat) in plasma. Finally, sex was identified as a covariate for $V / F$, which can be explained by the differences in body composition of male and female individuals. No influence of race or concomitant medication on the pharmacokinetics of vericiguat was observed.

Visual predictive checks showed agreement between the final model and the observed data and, overall, the general trend was well described. Importantly, qualification of the model demonstrated its suitability in predicting vericiguat exposure in patient subgroups of special interest, and it will 
Table 3 Parameter estimates for the NT-proBNP model

\begin{tabular}{llllc}
\hline Parameter & Units & Estimate & $95 \%$ CI from bootstrap & Shrinkage (\%) \\
\hline$T V k_{\text {in }}$ & $\mathrm{pg} / \mathrm{mL} /$ day & 77.4 & $46.4-126.9$ & \\
{$[\mathrm{NT}-\text { proBNP }]_{\text {baseline }}$} & $\mathrm{pg} / \mathrm{mL}$ & 3140 & $2857-3482$ & \\
$\theta_{k_{\text {in }}, \text { NT-proBNP }}$ & & 0.347 & $0.304-0.405$ & \\
$k_{\text {out_max }}$ & day $^{-1}$ & 0.157 & $0.086-0.330$ & \\
$E_{\max }$ & & $0.95 \mathrm{FIX}$ & & \\
EC $_{50}$ & $\mathrm{pg} / \mathrm{mL}$ & 439 & $233-792$ & 22.2 \\
ATRT & $\mathrm{L} / \mathrm{h} / \mathrm{mg}$ & 0.0176 & $0.024-0.360$ & 3.0 \\
$\omega^{2}\left(\mathrm{IIV} \mathrm{k}_{\text {in }}\right)$ & & 0.163 & $0.104-0.240$ & 15.4 \\
$\omega^{2}$ (IIV [NT-proBNP $\left.]_{\text {baseline }}\right)$ & & 0.953 & $0.814-1.089$ & \\
$\sigma^{2}$ (additive residual error) & & 0.145 & $0.129-0.161$ & \\
\hline
\end{tabular}

ATRT parameter describing the inhibition of $k_{\text {in }}$ by the 24-h area under the plasma concentrationtime curve of vericiguat through a linear model, $[N T-p r o B N P]_{\text {baseline }}$ baseline plasma concentration of NT-proBNP, $C I$ confidence interval, $E C_{50}$ concentration at which the inhibition of $k_{\text {out max }}$ is half of its maximum extent, $E_{\max }$ parameter describing the maximum extent that $k_{\text {out }}$ can be reduced through an increase in concentration of NT-proBNP, $T V k_{\text {in }}$ zero-order rate constant describing the production of NT-proBNP in a subject with a median baseline concentration of NT-proBNP in the absence of treatment with vericiguat, $k_{\text {out_max }}$ parameter describing the maximum value of the first-order rate constant for elimination of NT-proBNP, $N T$-proBNP $N$-terminal pro-B-type natriuretic peptide, $\sigma^{2}$ variance of additive residual error in concentration of NT-proBNP when modeled after logarithmic transformation, $\omega^{2}$ (IIV $[\mathrm{NT} \text {-proBNP }]_{\text {baseline }}$ ) variance of exponential inter-individual variability in $[\mathrm{NT}-\text { proBNP }]_{\text {baseline }}, \omega^{2}$ (IIV $\left.k_{\text {in }}\right)$ variance of exponential inter-individual variability in kin, $\theta_{k_{\mathrm{in}, \mathrm{NT}-\mathrm{proBNP}}}$ parameter describing the influence of [NT-proBNP $]_{\text {baseline }}$ on $k_{\text {in }}$

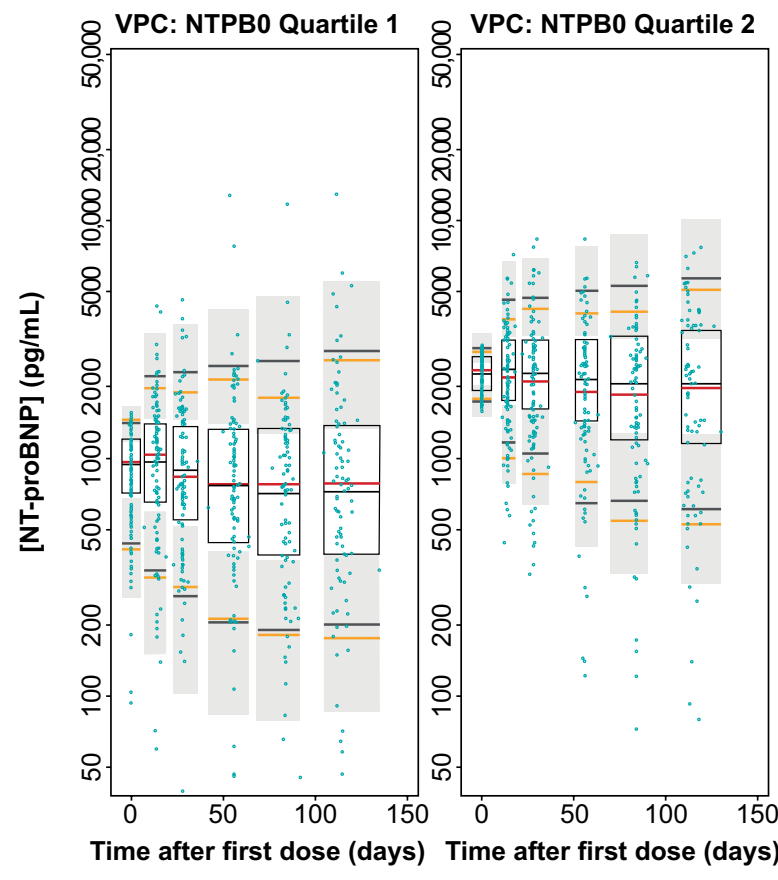

Fig. 6 Visual predictive check (VPC) of absolute [NT-proBNP] simulations from pharmacokinetic/pharmacodynamic (PK/PD) model with study data from SOCRATES-REDUCED stratified by the four quartiles of [NT-proBNP $]_{\text {baseline }}$ plasma concentration. Red lines: medians of observed data. Yellow lines: 10th and 90th percentiles of observed data. Unshaded boxes: 95\% confidence intervals (CIs) around the median of simulated data. Gray shaded boxes: $95 \%$ CIs around 10th

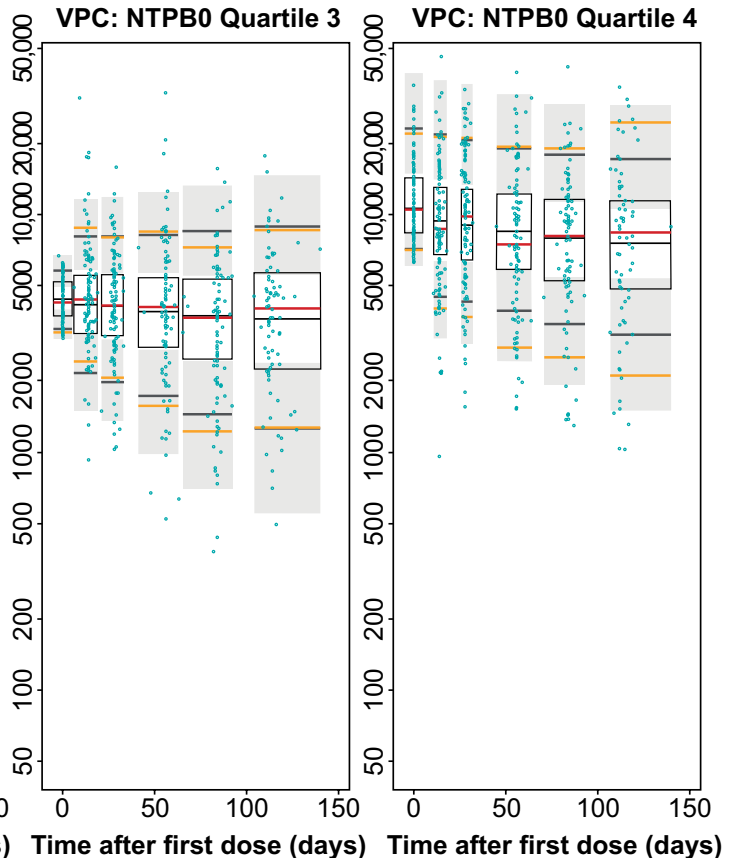

and 90th percentiles of simulated data. Blue points: observed data NTPB0 quartile 1/2/3/4: patients assigned to first/second/third/fourth quartiles of [NT-proBNP] $]_{\text {baseline }}$ according to fixed boundaries (94.1$1559 \mathrm{pg} / \mathrm{mL}, 1559-3000 \mathrm{pg} / \mathrm{mL}, 3000-6246 \mathrm{pg} / \mathrm{mL}, 6246-69,720$ $\mathrm{pg} / \mathrm{mL}$ ). NT-proBNP $N$-terminal pro-B-type natriuretic peptide, $[N T \text {-proBNP }]_{\text {baseline }}$ concentration of NT-proBNP at baseline 
Fig. 7 Simulated $N$-terminal pro-B-type natriuretic peptide (NT-proBNP) concentrationtime profiles under vericiguat $10 \mathrm{mg}$ on top of standard of care (SoC) or for SoC alone (a) and simulated absolute

NT-proBNP change compared with SoC (b). Solid lines: simulated NT-proBNP time courses for vericiguat $10 \mathrm{mg}$. Dashed lines: simulations for the corresponding $\mathrm{SoC}$ arm.

$[\mathrm{NT} \text {-proBNP }]_{\text {baseline }}$ considered for simulation: $250 \mathrm{pg} / \mathrm{mL}$ (gray), $500 \mathrm{pg} / \mathrm{mL}$ (orange), $1000 \mathrm{pg} / \mathrm{mL}$ (green), 3000 $\mathrm{pg} / \mathrm{mL}$ (purple), $5000 \mathrm{pg} / \mathrm{mL}$ (light blue), and $10,000 \mathrm{pg} / \mathrm{mL}$ (dark blue)
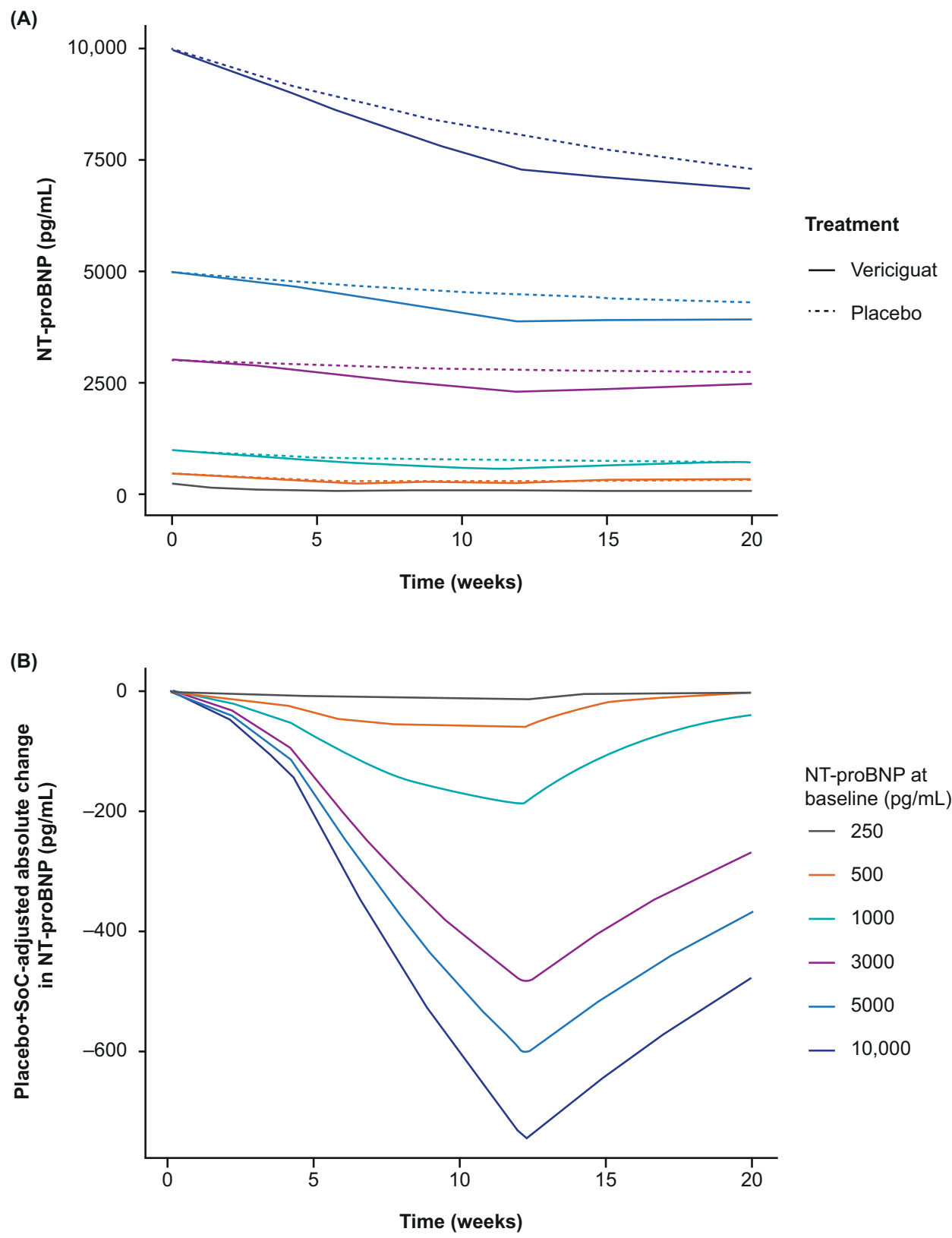

provide reliable exposure estimates for exposure-response analyses.

\subsection{PK/PD Correlation Analysis}

Correlation of individual vericiguat maximum concentration values with corresponding short-term SBP changes after dosing demonstrated minor effects of vericiguat on BP, with a low clinical impact at initial co-administration with SoC, and no long-term effects on BP, supportive of up-titration in patients with $\mathrm{HF}$ and LVEF $<45 \%$, if tolerated. This might be due to the influence of cardiac effects, such as increasing stroke volume in response to afterload reduction, which contribute to the long-term maintenance of BP after the transient short-term decrease. For HR, no changes from predose to post-dose at visit 1 or visit 4 were distinguishable.

\subsection{PK/PD Modeling of NT-proBNP}

This analysis provides the first published PK/PD modeling approach for NT-proBNP in patients with HF. Few exposure-response models for NT-proBNP in other indications are available in the literature. For example, an indirect PD model with transit compartments was developed that best described the relationship of doxorubicin exposure and acute NT-proBNP response in patients with breast cancer [35]. For the oral, selective, prostacyclin receptor agonist selexipag, approved for the treatment of pulmonary arterial 
Fig. 8 Results of $N$-terminal pro-B-type natriuretic peptide (NT-proBNP) pharmacokinetic/ pharmacodynamic

(PK/PD) simulation (expressed as ratio to standard of care [SoC]) displayed as stratified boxplots. Data were assigned to first/second/third/fourth quartiles (Q1/Q2/Q3/Q4) of $[\mathrm{NT} \text {-proBNP }]_{\text {baseline }}$ according to fixed boundaries (94.1-1559 $\mathrm{pg} / \mathrm{mL}, 1559-3000 \mathrm{pg} / \mathrm{mL}$, $3000-6246 \mathrm{pg} / \mathrm{mL}$, and 6246$69,720 \mathrm{pg} / \mathrm{mL}$ ). Blue points: median of $[\text { NT-proBNP }]_{\text {day } 84} /$ $[\mathrm{NT} \text {-proBNP }]_{\text {baseline }}$ divided by the corresponding SoC median of $[\mathrm{NT}-\text { proBNP }]_{\mathrm{day} 84} /[\mathrm{NT}$ proBNP $]_{\text {baseline }}$ across patients from each simulation repeat

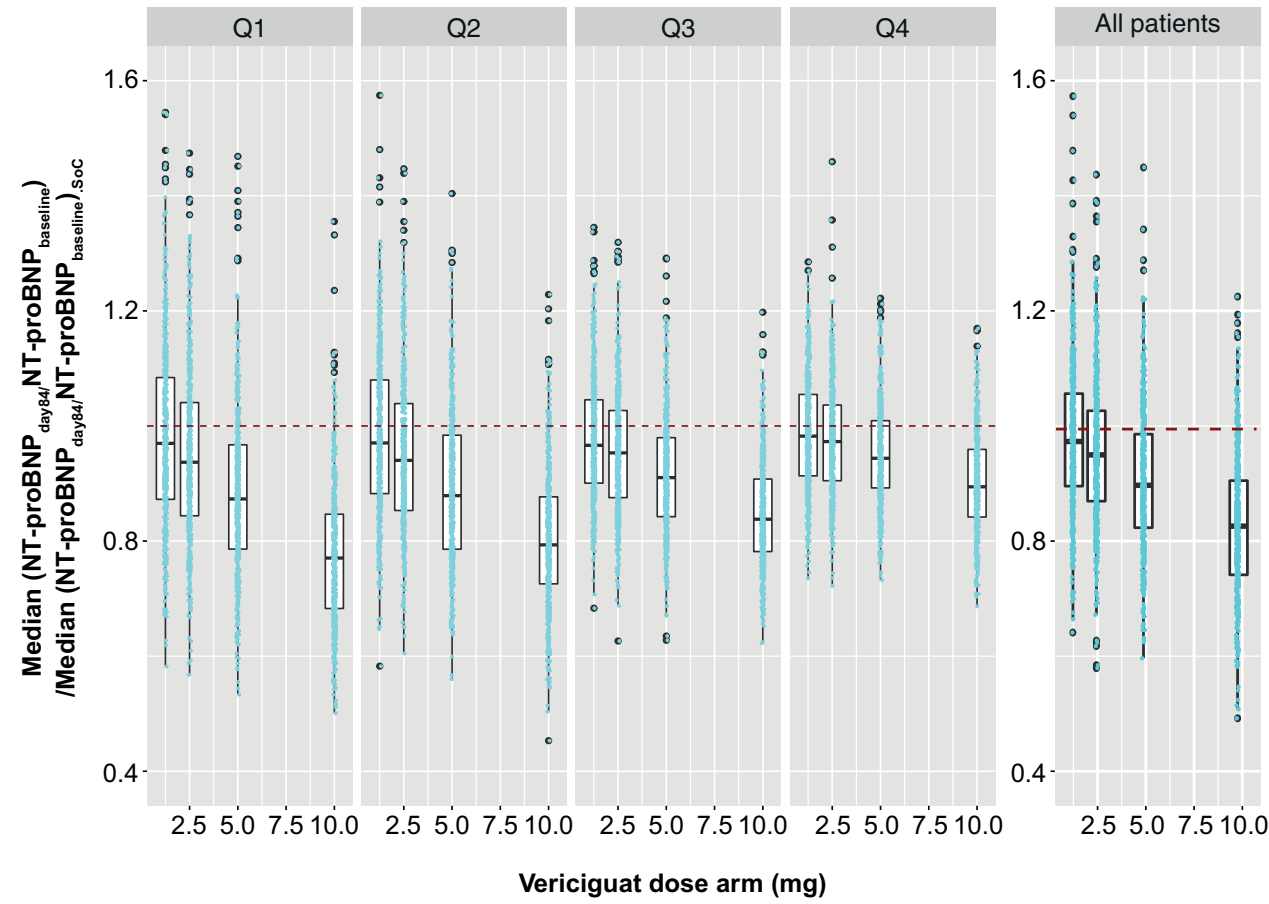

hypertension, a log-linear regression model was established linking model-predicted steady-state exposure to PD, and exposure to selexipag and NT-proBNP response at steady state [36]. Similar to the analysis presented here, Krause et al. reported a PK/PD model in a SoC situation whereby patients were receiving concomitant medications, which did not affect exposure to the study drug.

In this study, a semi-mechanistic turnover model was developed to relate vericiguat exposure to changes in [NT-proBNP], which considers a production rate as a surrogate for the physiological release of natriuretic peptide levels in HF in response to increased myocardial stress and an elimination rate as a surrogate for urinary excretion [33]. Visual predictive checks of the PK/PD model for NT-proBNP showed good overall agreement between model predictions and the observed data.

The main observations from PK/PD simulations of NT-proBNP were that vericiguat, on top of SoC, led to a stronger NT-proBNP decrease than $\mathrm{SoC}$ alone for all simulated $[\mathrm{NT}-\mathrm{proBNP}]_{\text {baseline }}$ categories, including the two categories of $250 \mathrm{pg} / \mathrm{mL}$ and $500 \mathrm{pg} / \mathrm{mL}$, which are below the minimal entry criterion in SOCRATES $(1000 \mathrm{pg} / \mathrm{mL})$. Although the relative difference of mean change with vericiguat from placebo at 12 weeks in the lowest baseline NT-proBNP category (250 $\mathrm{pg} / \mathrm{mL}$ ) was not as high as that in the $1000-\mathrm{pg} / \mathrm{mL}$ baseline category, the pronounced simulated treatment effect in the $500-\mathrm{pg} / \mathrm{mL}$ baseline NT-proBNP category suggests the potential for NT-proBNP-lowering capacity of vericiguat in patients with NT-proBNP levels below the studied cut-off point of $1000 \mathrm{pg} / \mathrm{mL}$. The upper limit of the interquartile range for [NT-proBNP] at baseline was $6246 \mathrm{pg} / \mathrm{mL}$, larger than the upper limit of the interquartile range reported in other trials in patients with HF with reduced ejection fraction. For example, the upper limit of the interquartile range was $2655 \mathrm{pg} / \mathrm{mL}$ in the DAPA-HF study [37] and 3305 $\mathrm{pg} / \mathrm{mL}$ in the PARADIGM-HF study (both sacubitril/valsartan and enalapril treatment arms) [38].

Simulations demonstrated that during the course of 12 weeks of treatment, steeper NT-proBNP declines were discernible for high baseline NT-proBNP levels compared with low baseline levels. Maximum response in the high-dose vericiguat groups was not reached during the 12 weeks of the study, suggesting that treatment longer than 12 weeks may induce even larger NT-proBNP decreases.

The differences between placebo and vericiguat, in terms of a NT-proBNP decrease from baseline, continued to separate at 12 weeks when study drug treatment was complete (especially for high NT-proBNP baseline levels). Extrapolation suggests the potential for even larger vericiguat-induced NT-proBNP decreases following long-term treatment, which requires further exploration with the longitudinal data from the VICTORIA study (NCT0286534) [14].

After cessation of treatment at 12 weeks, the simulations indicated a sustained difference between vericiguat on top of $\mathrm{SoC}$ and $\mathrm{SoC}$ alone, which was longer for higher NT-proBNP baseline levels. From week 12 (treatment completion) to week 20 (end of simulation period), simulated NT-proBNP levels only slowly converged in the vericiguat and placebo arms. 
While drug-induced effects on natriuretic peptides may not always reflect effects on clinical endpoints, we have demonstrated that, after short treatment durations of less than 10 weeks, NT-proBNP levels predict hazard ratios with confidence levels comparable to the final trial readout [39].

Interestingly, the effect of vericiguat on top of $\mathrm{SoC}$ was not linear, but dependent on [NT-proBNP $]_{\text {baseline }}$ as an indicator of disease severity and cardiac wall stress (Fig. 7b). For patients with [NT-proBNP] $]_{\text {baseline }}$ of $250,500,1000$, 3000,5000 , or $10,000 \mathrm{pg} / \mathrm{mL}$, the absolute [NT-proBNP] changes were $11 \mathrm{pg} / \mathrm{mL}(5 \%), 58 \mathrm{pg} / \mathrm{mL}(12 \%), 183$ $\mathrm{pg} / \mathrm{mL}(18 \%), 478 \mathrm{pg} / \mathrm{mL}$ (16\%), $593 \mathrm{pg} / \mathrm{mL}$ (12\%), and 734 $\mathrm{pg} / \mathrm{mL}$ (7\%), respectively. This non-linear trend was also observed in the VICTORIA study, in which the effect of vericiguat on the primary outcome was different in the subgroups defined according to the NT-proBNP level [14], and is hypothesized here to be due to the implemented inhibitory effect of [NT-proBNP] on $k_{\text {out }}$, reflecting the physiologically observed reduction of NT-proBNP clearance via the kidneys, as observed in 94 patients with chronic HF and increasing [NT-proBNP] [33]. Further model-based evaluations of the VICTORIA study data are warranted to further investigate the clinical relevance of the predicted and observed effect of $[\mathrm{NT} \text {-proBNP }]_{\text {baseline }}$ on [NT-proBNP] changes. Nevertheless, in patients with high baseline NT-proBNP, the simulations supported up-titration to vericiguat $10 \mathrm{mg}$, if tolerated.

\section{Conclusions}

Vericiguat has predictable pharmacokinetics in patients with $\mathrm{HF}$ and LVEF $<45 \%$, with a slight decrease of bioavailability with increasing dose. Vericiguat had minor effects on BP, with low clinical impact at initial coadministration with SoC, and no long-term effects on $\mathrm{BP}$ in patients with $\mathrm{HF}$ and LVEF $<45 \%$. There were no changes in HR from pre-dose to post-dose at visit 1 or visit 4. Pharmacokinetic/ pharmacodynamic modeling of change in [NT-proBNP] from baseline showed an exposure-dependent reduction of [NT-proBNP] with vericiguat, which was dependent on baseline [NT-proBNP], an indicator of disease severity. The NT-proBNP-lowering effect of vericiguat added to SoC was more pronounced than that for placebo with SoC for all simulated baseline [NT-proBNP] categories, including $<1000$ $\mathrm{pg} / \mathrm{mL}$ (minimal entry criterion of SOCRATES-REDUCED $\geq 1000 \mathrm{pg} / \mathrm{mL}$ ), suggesting a potential NT-proBNP-lowering capacity of vericiguat in patients with NT-proBNP $<1000$ $\mathrm{pg} / \mathrm{mL}$. Pharmacokinetic/pharmacodynamic modeling of NT-proBNP suggests that vericiguat treatment longer than 12 weeks could induce even larger NT-proBNP decreases and requires further investigation. This analysis supported further evaluation of vericiguat $10 \mathrm{mg}$ once daily in the phase III VICTORIA study.
Supplementary Information The online version contains supplementary material available at https://doi.org/10.1007/s40262-021-01024-y.

Acknowledgements The authors dedicate the article to the late Mihai Gheorghiade, who served as the co-chair of the SOCRATES steering committee. We gratefully acknowledge Maria Trujillo, Marissa Dockendorf, and Anne Chain from Merck Sharp \& Dohme Corp., a subsidiary of Merck \& Co., Inc., Kenilworth, NJ, USA for their contributions to the study. Part of this analysis was presented at the European Society of Cardiology Heart Failure Congress 2019. Medical writing support was provided by Maximilian Becker and Simone Steinbach of Bayer AG. Editorial support, including fact checking, referencing, figure preparation, formatting, proofreading, and submission, was provided by Laila Guzadhur and Annabel Ola of Scion, London, UK supported by Bayer AG, Berlin and Merck Sharp \& Dohme Corp., a subsidiary of Merck \& Co., Inc., Kenilworth, NJ, USA according to Good Publication Practice guidelines. The sponsors were involved in the study design, collection, analysis, and interpretation of data, as well as data checking of information provided in the article. However, ultimate responsibility for opinions, conclusions, and data interpretation lies with the authors.

\section{Declarations}

Funding This work was supported by Bayer AG, Berlin, Germany and Merck Sharp \& Dohme Corp., a subsidiary of Merck \& Co., Inc., Kenilworth, NJ, USA.

Conflicts of Interest/Competing Interests Hauke Ruehs, Dagmar Klein, Matthias Frei, Corina Becker, Lothar Roessig, Dirk Garmann, and Michaela Meyer are employees and potential stockholders of Bayer AG and may own stock in the company. Joachim Grevel and Rupert Austin are employees of BAST Inc. Limited and paid consultants for Bayer Healthcare Pharmaceuticals. Burkert Pieske served as the Study Chair on the Executive Committee of SOCRATES and received advisory honoraria and speakers' fees from Bayer Healthcare and Merck Sharp \& Dohme Corp., a subsidiary of Merck \& Co., Inc., Kenilworth, NJ, USA.

Ethics approval The SOCRATES-REDUCED protocol was approved by the ethics committee or institutional review board of each study site. The study was conducted in accordance with the Declaration of Helsinki and adhered to the International Conference of Harmonization good clinical practice guidelines.

Consent to Participate Informed consent was obtained from all individual participants included in the study.

Consent for Publication Not applicable.

Availability of Data and Material Availability of the data underlying this publication will be determined according to Bayer's commitment to the EFPIA/PhRMA "Principles for responsible clinical trial data sharing". This pertains to scope, timepoint, and process of data access. As such, Bayer commits to sharing upon request from qualified scientific and medical researchers patient-level clinical trial data, studylevel clinical trial data, and protocols from clinical trials in patients for medicines and indications approved in the USA and European Union as necessary for conducting legitimate research. This applies to data on new medicines and indications that have been approved by the European Union and US regulatory agencies on or after 1 January, 2014. Interested researchers can use http://www.clinicalstudydatarequest. com to request access to anonymized patient-level data and supporting documents from clinical studies to conduct further research that can 
help advance medical science or improve patient care. Information on the Bayer criteria for listing studies and other relevant information is provided in the study sponsors section of the portal. Data access will be granted to anonymized patient-level data, protocols, and clinical study reports after approval by an independent scientific review panel. Bayer is not involved in the decisions made by the independent review panel. Bayer will take all necessary measures to ensure that patient privacy is safeguarded.

\section{Code availability Not applicable.}

Authors' contributions All authors were involved in at least one of the following: conception, design of work or acquisition, analysis, interpretation of data, and drafting the manuscript and/or revising/reviewing the manuscript for important intellectual content.

Open Access This article is licensed under a Creative Commons Attribution-NonCommercial 4.0 International License, which permits any non-commercial use, sharing, adaptation, distribution and reproduction in any medium or format, as long as you give appropriate credit to the original author(s) and the source, provide a link to the Creative Commons licence, and indicate if changes were made. The images or other third party material in this article are included in the article's Creative Commons licence, unless indicated otherwise in a credit line to the material. If material is not included in the article's Creative Commons licence and your intended use is not permitted by statutory regulation or exceeds the permitted use, you will need to obtain permission directly from the copyright holder. To view a copy of this licence, visit http://creativecommons.org/licenses/by-nc/4.0/.

\section{References}

1. Benjamin EJ, Virani SS, Callaway CW, Chamberlain AM, Chang AR, Cheng S, et al. Heart disease and stroke statistics: 2018 update A report from the American Heart Association. Circulation. 2018;137(12):e67-492.

2. Cook C, Cole G, Asaria P, Jabbour R, Francis DP. The annual global economic burden of heart failure. Int J Cardiol. 2014;171(3):368-76.

3. Vos T, Abajobir AA, Abate KH, Abbafati C, Abbas KM, AbdAllah F, et al. Global, regional, and national incidence, prevalence, and years lived with disability for 328 diseases and injuries for 195 countries, 1990-2016: a systematic analysis for the Global Burden of Disease Study 2016. Lancet. 2017;390(10100):1211-59.

4. Ponikowski P, Voors AA, Anker SD, Bueno H, Cleland JG, Coats AJ, et al. Eur J Heart Fail. 2016;18(8):891-975.

5. Butler J, Yang M, Manzi MA, Hess GP, Patel MJ, Rhodes T, et al. Clinical course of patients with worsening heart failure with reduced ejection fraction. J Am Coll Cardiol. 2019;73(8):935-44.

6. Weber M, Hamm C. Role of B-type natriuretic peptide (BNP) and NT-proBNP in clinical routine. Heart. 2006;92(6):843-9.

7. Yancy CW, Jessup M, Bozkurt B, Butler J, Casey DE Jr, Colvin $\mathrm{MM}$, et al. 2017 ACC/AHA/HFSA focused update of the $2013 \mathrm{ACCF} / \mathrm{AHA}$ guideline for the management of heart failure: a report of the American College of Cardiology/American Heart Association Task Force on Clinical Practice Guidelines and the Heart Failure Society of America. Circulation. 2017;136(6):e137-61.

8. McKie PM, Burnett JC Jr. NT-proBNP: the gold standard biomarker in heart failure. J Am Coll Cardiol. 2016;68(22):2437-9.

9. Boerrigter G, Lapp H, Burnett JC. Modulation of cGMP in heart failure: a new therapeutic paradigm. Handb Exp Pharmacol. 2009; 191:485-506.
10. Brutsaert DL. Cardiac endothelial-myocardial signaling: its role in cardiac growth, contractile performance, and rhythmicity. Physiol Rev. 2003;83(1):59-115.

11. Sandner P. From molecules to patients: exploring the therapeutic role of soluble guanylate cyclase stimulators. Biol Chem. 2018;399(7):679-90.

12. Gheorghiade M, Marti CN, Sabbah HN, Roessig L, Greene SJ, Bohm M, et al. Soluble guanylate cyclase: a potential therapeutic target for heart failure. Heart Fail Rev. 2013;18(2):123-34.

13. Sandner P, Zimmer DP, Milne GT, Follmann M, Hobbs A, Stasch JP. Soluble guanylate cyclase stimulators and activators. Handb Exp Pharmacol. 2021;264:355-94.

14. Armstrong PW, Roessig L, Patel MJ, Anstrom KJ, Butler J, Voors AA, et al. A multicenter, randomized, double-blind, placebocontrolled trial of the efficacy and safety of the oral soluble guanylate cyclase stimulator: the VICTORIA trial. JACC Heart Fail. 2018;6(2):96-104.

15. Armstrong PW, Pieske B, Anstrom KJ, Ezekowitz J, Hernandez $\mathrm{AF}$, Butler $\mathrm{J}$, et al. Vericiguat in patients with heart failure and reduced ejection fraction. N Engl J Med. 2020;382(20):1883-93.

16. US Food and Drug Administration. Verquvo ${ }^{\mathrm{TM}}$ prescribing information. 2021. https://www.accessdata.fda.gov/drugsatfda_docs/ label/2021/214377s000lbl.pdf. Accessed 8 Feb 2021.

17. Boettcher M-F, Thomas D, Mueck W, Loewen S, Arens E, Yoshikawa K, et al. Safety, pharmacodynamic and pharmacokinetic characterisation of vericiguat: key results from six phase I studies in healthy subjects. Eur J Heart Fail. 2019;21(Suppl S1):293.

18. Lobmeyer M, Gerisch M, Boettcher M-F, Thomas D, Gerrits M, Mueck W, et al. Metabolism and pharmacokinetic drug interaction profile of vericiguat, a soluble guanylate cyclase stimulator. Eur J Heart Fail; 2019. p. 425. https://esc365.escardio.org/Congress/ Heart-Failure-2019-6th-World-Congress-on-Acute-Heart-Failure/ Poster-Session-3-Chronic-Heart-Failure-Treatment/194204-metab olism-and-pharmacokinetic-drug-interaction-profile-of-veric iguat-a-soluble-guanylate-cyclase-stimulator\#abstract.

19. Bhatt DK, Mehrotra A, Gaedigk A, Chapa R, Basit A, Zhang $\mathrm{H}$, et al. Age- and genotype-dependent variability in the protein abundance and activity of six major uridine diphosphateglucuronosyltransferases in human liver. Clin Pharmacol Ther. 2019;105(1):131-41.

20. Margaillan G, Rouleau M, Fallon JK, Caron P, Villeneuve L, Turcotte V, et al. Quantitative profiling of human renal UDPglucuronosyltransferases and glucuronidation activity: a comparison of normal and tumoral kidney tissues. Drug Metab Dispos. 2015;43(4):611-9.

21. Gheorghiade M, Greene SJ, Butler J, et al. Effect of vericiguat, a soluble guanylate cyclase stimulator, on natriuretic peptide levels in patients with worsening chronic heart failure and reduced ejection fraction: the SOCRATES-REDUCED randomized trial. J Am Med Assoc. 2015;314:2251-62.

22. Pieske B, Butler J, Filippatos G, Lam C, Maggioni PA, Ponikowski $\mathrm{P}$, et al. Rationale and design of the SOluble guanylate Cyclase stimulatoR in heArT failurE Studies (SOCRATES). Eur J Heart Fail. 2014;16:1026-38.

23. Boettcher M, Gerisch M, Lobmeyer M, Besche N, Thomas D, Gerrits M, et al. Metabolism and pharmacokinetic drug-drug interaction profile of vericiguat, a soluble guanylate cyclase stimulator: results from preclinical and phase I healthy volunteer studies. Clin Pharmacokinet. 2020;11:1407-18.

24. Boettcher M, Thomas D, Mueck W, Loewen S, Arens E, Yoshikawa K, et al. Safety, pharmacodynamic, and pharmacokinetic characterization of vericiguat: results from six phase I studies in healthy subjects. Eur J Clin Pharmacol. 2021;77:527-37.

25. US Food and Drug Administration. Bioanalytical method validation: guidance for industry. 2018. https://www.fda.goV/Files/ 
drugs/published/Bioanalytical-Method-Validation-Guidance-forIndustry.pdf. Accessed 22 Mar 2019.

26. R Core Team (2014) R: a language and environment for statistical computing. Vienna: R Foundation for Statistical Computing; 2014.

27. Cockcroft DW, Gault MH. Prediction of creatinine clearance from serum creatinine. Nephron. 1976;16(1):31-41.

28. Mould DR, Holford NH, Schellens JH, Beijnen JH, Hutson PR, Rosing H, et al. Population pharmacokinetic and adverse event analysis of topotecan in patients with solid tumors. Clin Pharmacol Ther. 2002;71(5):334-48.

29. Mandema JW, Verotta D, Sheiner LB. Building population pharmacokinetic-pharmacodynamic models. Models for covariate effects. J Pharmacokinet Biopharm. 1992;20(5):511-28.

30. Karlsson MO, Holford N. A tutorial on visual predictive checks. In: Annual Meeting of the Population Approach Group in Europe, 18-20th June 2008; Marseille.

31. Bergstrand M, Hooker AC, Wallin JE, Karlsson MO. Prediction-corrected visual predictive checks for diagnosing nonlinear mixed-effects models. AAPS J. 2011;13(2):143-51.

32. Holford NH. A size standard for pharmacokinetics. Clin Pharmacokinet. 1996;30(5):329-32.

33. Linssen GC, Damman K, Hillege HL, Navis G, van Veldhuisen DJ, Voors AA. Urinary N-terminal prohormone brain natriuretic peptide excretion in patients with chronic heart failure. Circulation. 2009;120(1):35-41.
34. Follmann M, Ackerstaff J, Redlich G, Wunder F, Lang D, Kern A, et al. Discovery of the soluble guanylate cyclase stimulator vericiguat (BAY 1021189) for the treatment of chronic heart failure. J Med Chem. 2017;60(12):5146-61.

35. Liang S, Brundage RC, Jacobson PA, Blaes A, Kirstein MN. Pharmacokinetic-pharmacodynamic modelling of acute $\mathrm{N}$-terminal pro B-type natriuretic peptide after doxorubicin infusion in breast cancer. Br J Clin Pharmacol. 2016;82(3):773-83.

36. Krause A, Machacek M, Lott D, Hurst N, Bruderer S, Dingemanse J. Population modeling of selexipag pharmacokinetics and clinical response parameters in patients with pulmonary arterial hypertension. CPT Pharmacometr Syst Pharmacol. 2017;6(7):477-85.

37. McMurray JJV, Solomon SD, Inzucchi SE, Kober L, Kosiborod MN, Martinez FA, et al. Dapagliflozin in patients with heart failure and reduced ejection fraction. N Engl J Med. 2019;381(21):1995-2008.

38. McMurray JJ, Packer M, Desai AS, Gong J, Lefkowitz MP, Rizkala AR, et al. Angiotensin-neprilysin inhibition versus enalapril in heart failure. N Engl J Med. 2014;371(11):993-1004.

39. Schmitt W, Rühs H, Burghaus R, Diedrich C, Duwal S, Eissing T, et al. NT-proBNP qualifies as a surrogate for clinical endpoints in heart failure. Clin Pharmacol Ther. 2021. https://doi.org/10.1002/ cpt.2222.

40. Bonate PL. Pharmacokinetic-pharmacodynamic modeling and simulation. 2nd ed. Boston, MA: Springer; 2011. 